\title{
Editorial
}

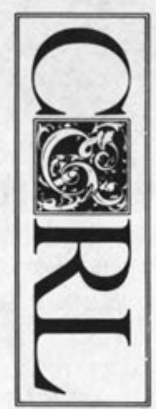

\section{Creative Behavior in Libraries}

On April 17, Raymond Miles, dean of the School of Business Administration at Berkeley, delivered a visiting scholar lecture. His topic was organizations in the future. The substance of his remarks might be summarized as "everything that is not tied down is coming apart." [See Raymond Miles and Charles Snow, "Designing Strategic Human Resources Systems," Organizational Dynamics (Summer 1984).] Since it was Earthquake Preparedness Week in California, I found a certain irony in his conclusion. As a librarian, I felt a certain alarm. Cards flying from the catalog, order slips falling apart, and books reappearing randomly on the shelf were among the images that entered my mind.

How can libraries operate in a "coming apart" environment? Aren't we charged with creating order out of chaos-bibliographic order out of publishing chaos? We select resources and organize them for use. We develop intermediary functions to assist users in coping with the order that we have created. These activities are formal and rather precise. In order for us to cope with the future and the demands of a Knowledge Society, it seems that we must also develop creative responses to dramatic changes. How?

In my mind, creativity implies somewhat alien qualities - the generation of ideas on a random basis, the suspension of disbelief, and the exploration of the mysteries of abstract thinking. [See Min Basadur and Carl T. Finkbeiner, "Measuring Preference for Ideation in Creative Problem-Solving Training," Journal of Applied Behavioral Science (Feb. 1985).] In librarianship we follow rules (e.g., AACR2) and attempt to arrive at quick closure (e.g., the reference interchange).

Creativity implies freedom, deciding what to do and how to do it.

When people are inspired by their own interests and enjoyment there is a better chance that they will explore unlikely paths, take risks and, in the end, produce something unique and useful. [Daniel P. Haney, "Creativity: A Drive From Within," Sacramento Bee (Feb. 3, 1985), p.A22.]

There is a degree of leisure that is usually associated with the creative process. In librarianship, leisure has been depicted as a luxury that we can ill afford given the many service demands that we face. Furthermore, traditional forms of bureaucracy do not encourage the practice of creativity. Business organizations create research and development (R and D) groups and organize them according to different principles as one means for offsetting this deficiency.

Libraries are experiencing dramatic changes. These changes signify that important adaptive behaviors are occurring. I tend to categorize these behaviors as coping mechanisms. I do not believe that they are creative behaviors. This judgment is personal and is based on the belief that the act of creation brings forth something new and unique. Few of our adaptive behaviors, however, fall into this category. Our efforts are largely extensions of what is known.

Some trends in the information world are momentous in their implications for the future direction of academic librarianship. They seem to demand not coping but creative responses. Today, many members of the computer world are confused by the rapid changes that they are experiencing. The impact of laser, microwave, computer, and other related 
technologies may be overwhelming our ability to see a path through the thicket. At one time ten-year plans seemed feasible. Now the experts question the utility of five-year plans. Indeed, strategic planning may be in vogue mainly because some organizations realize that they need to revise their planning assumptions and goals at a rapid rate (e.g., monthly or semiannually). We have entered a period of turbulence.

Recently, I heard the advice that libraries should expect to change their automated systems every five to seven years. Some libraries have taken this long just to make the decision to purchase an automated system. Getting the funding for such a system presents additional obstacles and more time.

In the early 1970s I felt comfortable with my knowledge of online reference as a technology and as a form of service. Today, I am not only unable to keep up but I am confused. A newspaper, Information Today, tracks developments. It is but one symptom of a turbulent environment. In the past, trends in library automation could be plotted with relative ease. The trends moved through libraries based on functional needs-circulation, acquisitions, and cataloging. Now we can see a shift toward reference-type systems. Immediately, with this shift, the scope and range of possibilities increase dramatically. Simultaneously, transmission and storage technologies are multiplying rapidly and some of these technologies are in direct competition with one another. This compounds our problems so that typical coping mechanisms may no longer work. Again, creative responses are required.

How can we learn to think in new and unique ways about our problems? It will be difficult. In my opinion we will have to examine old assumptions. First, we need to examine the historical basis of librarianship. Let me give a few examples of some of the questions that might be raised and the assumptions that might be challenged.

- What business are we in? One might say that we are in the container business. We label the containers and we circulate the containers. Given the work load of these tasks it is sometimes difficult for librarians to help users to interpret the labels and to select among containers.

- What business should we be in? One might say that we should be in the content business. When I buy a carton of milk, I rarely observe the brand or spend time on examining the container. I'm interested in the milk. As librarians we should be interested in content, ideas. Perhaps these ideas should be organized to help people to solve problems.

- Should library collections be the base from which all other activities are derived? One might say that books on the shelf represent static information. Should we create a new base, a base of dynamic information? Information might be organized at the time it is needed to help the user solve a problem. The organization of information would be tailored to individual needs.

- Should we conceive of developing information sources not through local collections but through new, unimagined uses of physical and mental technologies?

In this issue of CERL the second part of Allen Veaner's article "1985 to 1995: The Next Decade in Academic Librarianship'" appears. He has created for us a synthesis, an organized perspective of the future. It should help us to understand what might happen in the future and what role we as librarians should play. Jane Robbins-Carter, Johannah Sherrer, Deborah Jakubs, and Charles Lowry offer their comments on Veaner's article in order to provide a critical perspective on various themes and issues. The need for more creative behavior is obvious. It will not come solely from reexamining the old and the worn. We also need to examine new territory.

CHARLES MARTELL 